\title{
Evidence of Plant-Soil Feedback in South Texas Grasslands Associated with Invasive Guinea Grass Independent of Soil Inoculation Method
}

Elizabeth A Bowman ( $\sim$ eabowman@utexas.edu )

The University of Texas at Austin https://orcid.org/0000-0002-9631-3559

Robert M. Plowes

The University of Texas at Austin

Lawrence E. Gilbert

The University of Texas at Austin

\section{Research Article}

Keywords: Guinea grass, Megathyrsus maximus, South Texas, grassland, plant-soil feedback

Posted Date: July 2nd, 2021

DOl: https://doi.org/10.21203/rs.3.rs-668160/v1

License: (c) (i) This work is licensed under a Creative Commons Attribution 4.0 International License.

Read Full License 


\section{Abstract}

Purpose: Plant-soil feedback plays a strong role in plant community composition, but the effect of invasive Guinea grass, Megathyrsus maximus, on these processes remains unexplored. Here, we aim to provide a first look at plant-soil feedback (PSF) process in South Texas savannahs currently undergoing invasion by Guinea grass. Our two main questions are (1) how does the presence of the invasive $M$. maximus alter PSF compared to non-invaded grasslands and (2) are these results robust to inoculation method.

Methods: Under greenhouse conditions, we assessed growth of Guinea grass and response of the native seed bank in soil collected from grasslands invaded by Guinea grass and native grasslands using two methods of soil inoculation: individual and pooled soil samples.

Results: Guinea grass grown in soil from invaded grasslands grew taller and accumulated higher biomass than in soil from non-invaded grasslands. Plants grown from the native seed bank were more species rich and abundant in soil from non-invaded grasslands but had higher biomass in soil from invaded grasslands. Overall, these results were robust to differences in inoculation method.

Conclusion: In South Texas savannahs, presence of Guinea grass is associated with changes in the direction of plant-soil feedback processes with negative feedback processes possibly contributing to species coexistence in non-invaded native grasslands while positive feedback processes appear to reinforce invasion by Guinea grass. Future work is needed to assign causality of these changes to Guinea grass itself and further explore the role plant-soil feedback has in Guinea grass invasion.

\section{Introduction}

Invasive species are a continuous and increasingly widespread concern due to their negative impacts on ecosystems and difficulty in controlling their spread (Assessment 2005; Pyšek and Richardson 2010). Invasion by non-natives reduces plant diversity with extreme cases resulting in monodominant stands and declines of wider biodiversity levels (Assessment 2005; Dogra et al. 2010). More broadly at the ecosystem level, invasion disrupts nutrient cycling, disturbance regimes, and microbial communities above- and belowground with long-term effects (Hawkes et al. 2005; D’Antonio and Flory 2017).

Invasive plant species can have a strong impact on below-ground processes through allelopathy or plantsoil feedback (PSF) processes which can reinforce invasion (see Batten et al., 2006; Belnap et al., 2005; Hawkes et al., 2005; Levine et al., 2006; Wolfe \& Klironomos, 2005). By altering soil abiotic and biotic conditions, PSF influences the subsequent growth and vigor of conspecific and heterospecific plants (Bever 1994; Van der Putten et al. 2013). The strength and direction of PSF is influenced by plants via litter, root exudates, and selection for microbial communities composed of diverse mutualists, pathogens, and saprotrophs (van der Putten et al. 2016), but can select for either heterospecifics (negative feedback) or conspecifics (positive feedback). In native grasslands and particularly among grasses, PSF has largely negative or stabilizing effects on plant growth, which contributes to species coexistence, succession and 
possibly facilitating invasion by non-natives (Kulmatiski et al. 2008; Hawkes et al. 2013; Lekberg et al. 2018). Invasion of non-natives may alter these processes with evidence for shifts to a largely positive PSF through a variety of pathways including a release from pressure of soil pathogens or allelopathic chemicals, the presence of generalist soil mutualists, or an increase in soil nutrient availability (Reinhart and Callaway 2006; Hawkes et al. 2013).

In South Texas, Guinea grass, Megathyrsus maximus (Jacq.) B.L. Simon and Jacobs, is emerging as a problematic invasive (CABI 2021). Although originally introduced as a forage crop in rangelands, Guinea grass has caused issues due to its rapid spread, low palatability, and negative effect on native plant and animal diversity (Rhodes et al.; Sands and Goolsby 2011; Wied et al. 2020). A perennial bunchgrass native to Kenya, Guinea grass, has been introduced in tropical areas globally as a pasture grass due to its fast growth, biomass accumulation, and stress tolerance, but these same traits that make Guinea grass a useful forage component also make it a successful invasive species (Rhodes et al., in review). Although aboveground contributions to the high competitive ability of Guinea grass are better understood (Ammondt and Litton 2012; D'Antonio and Flory 2017), little is known regarding how Guinea grass impacts belowground processes (but see Chou \& Young, 1975) and what role this may have in facilitating invasions.

Research into methods to control Guinea grass invasion have focused on removal of Guinea grass with herbicides, burn treatments, and grazing followed by reintroduction of natives from seeds or out plantings, but results have been mixed (Ramirez-Yanez et al. 2007; Ammondt and Litton 2012; Ammondt et al. 2013; Ellsworth et al. 2015). If Guinea grass does alter PSF processes toward a positive feedback for conspecifics, the reestablishment of native plants could be hindered even when Guinea grass is removed prior to plantings (Reinhart and Callaway 2006). A study conducted in Hawaii comparing establishment of natives from seeds versus out plantings after removal of Guinea grass found that field germination from seeds was extremely low ranging from $0.5-2.3 \%$ (Ammondt et al. 2013). Natives that were out planted performed better, although there was still a high level of variation with $38-67 \%$ surviving (Ammondt et al. 2013). The effect of PSF on the germination and growth of native plants from seeds, as well as established seed banks is relatively unexplored, although soil microbes are known to impact seed germination and survival (Zalamea et al. 2015; Sarmiento et al. 2017). Overall, the role PSFs play in Guinea grass invasion and its effect on regeneration from native seed banks remains unexplored.

Here, we conducted a first look at PSF in grasslands invaded by Guinea grass and non-invaded grasslands dominated by native species in South Texas savannahs. In addition to exploring broad patterns of PSF as a function of invasion, we aimed to establish a methodology for future work. A large source of variation in studies of PSF is application of soil inoculum with inoculum either kept as individual, independent inocula (individual soil sampling, ISS) or pooled to create a common inoculum for each treatment (mixed soil sampling, MSS) (Reinhart and Rinella 2016; Cahill et al. 2017; Gundale et al. 2019). MSS homogenizes soil nutrients, microbes and seed bank, which can remove the ability to measure within site variation and increase the chance of Type I errors (Gundale et al. 2019). In contrast, ISS clearly maintains the local sample integrity but at the cost of requiring greater replication to look at 
mean effects even across short distances. Our goals for this study were to assess the study system in South Texas for evidence of PSF and to evaluate variation in PSF using two inoculations (MSS and ISS). Here, we addressed two main questions:

1. What evidence is there of PSF in invaded and native grasslands (hereafter, non-invaded) in South Texas?

2. To what extent are these results robust to different soil inoculation methodologies?

We hypothesized that a) germination and growth of Guinea grass will be higher in soil from invaded grasslands than non-invaded grasslands, whereas germination and growth of the native plant community will be lower in invaded grasslands versus non-invaded, and b) PSF patterns will be similar across similar sites with MSS and ISS inoculation methods showing similar results. This study represents the first time that the effect of Guinea grass on PSF has been studied providing a baseline for understanding the role of PSF in Guinea grass invasion.

\section{Methods}

To test our hypotheses, we conducted a greenhouse experiment using soil collected from grasslands invaded by Guinea grass, Megathyrsus maximus, and non-invaded grasslands in Kleberg County (latitude: 27.433, longitude: -97.67) located in South Texas (August 2020). These grasslands are in a savannah matrix with patches of mesquite (Prosopis glandulosa) trees and receive on average $73.6 \mathrm{~cm}$ of rain per year (U.S. Climate Data). Sampled grasslands were located between 4 to $8 \mathrm{~km}$ apart spanning an area of approximately $5.5 \mathrm{~km}^{2}$. Soil from all sites was composed predominantly of sand (mean $92 \% \pm$ $1.8 \%$ ) with minor amounts of silt and clay (mean $5.7 \% \pm 0.8 \%$ and $2.3 \% \pm 1.5 \%$, respectively). Grasslands underwent mechanical disturbance in 2000 and were subject to grazing by cattle throughout the year.

\section{Sampling and experimental design}

Within each of three sites, we sampled soil from plots invaded by Guinea grass and non-invaded plots (i.e., predominantly native with no Guinea grass present) that were located within $10 \mathrm{~m}$ of each other. We collected five soil cores from each plot with individual cores located approximately $1 \mathrm{~m}$ apart. For each soil core, we removed the litter layer and excavated the soil using a hand trowel to a depth of $15 \mathrm{~cm}$. We collected two sets of soil: a) bulk soil for use as the growth medium and b) soil for use as inoculum in ISS and MSS treatments. Inoculum soils were collected individually in plastic bags. Within one week of collection, we sieved all soil (i.e., bulk and inoculum) using a $2 \mathrm{~mm}$ soil sieve to remove leaf litter and plant roots. Between each use, the sieve was sterilized with $0.5 \% \mathrm{NaOCl}$ for five minutes, washed with tap water, and allowed to air dry. To create MSS inoculum, we pooled inoculum based on invasion status for each of the three sites to create a common inoculum that was applied to replicates $(n=6$ inoculum pools). For ISS inoculum, we applied distinct (i.e., unpooled) inoculum to each replicate. 
Treatments included invasion status (invaded grassland, non-invaded grassland) and soil inoculation method (ISS, MSS) (Table I). Each cross was replicated five times with soil from three separate sites (20 samples per treatment, 60 samples total). We filled pots with unautoclaved bulk soil and then added soil inoculum (3\% mass : mass) to each pot with Guinea grass seeds (Van Der Putten et al. 2007). We did not autoclave the bulk soil as we found that autoclaving impacted soil characteristics with levels of phosphorus, sulfur, sodium, and electrical conductivity positively correlated to autoclave time (Supplementary Table SI). In each pot, we sowed approximately $0.015 \mathrm{~g}$ of Guinea grass seed collected from grasslands in South Texas. Although we were unable to quantify the native seed bank, we standardized the amount of soil that went into each pot in order to normalize the seed bank. To do this, we homogenized the bulk soil based on site and invasion status, then placed the same amount of soil and therefore inoculum as stated above - into each pot. We visually assessed the sieved litter for seeds to assess whether larger seeds were removed during soil sieving (i.e. size sorting of seeds), but noted only plant leaves and roots in the material removed during sieving.

Table I: Summary of sampling treatments and replication. MSS = Mixed soil sampling; ISS = Individual soil sampling.

\begin{tabular}{|llll|}
\hline Grassland site & Invasion status & Soil treatment & Replicates \\
\hline 1 & Invaded & ISS & 5 \\
\hline 1 & Invaded & MSS & 5 \\
\hline 1 & Non-invaded & ISS & 5 \\
\hline 2 & Non-invaded & MSS & 5 \\
\hline 2 & Invaded & ISS & 5 \\
\hline 2 & Invaded & MSS & 5 \\
\hline 2 & Non-invaded & ISS & 5 \\
\hline 3 & Non-invaded & MSS & 5 \\
\hline 3 & Invaded & ISS & 5 \\
\hline 3 & Invaded & MSS & 5 \\
\hline 3 & Non-invaded & ISS & 5 \\
\hline Total & Non-invaded & MSS & 5 \\
\hline
\end{tabular}

\section{Germination and growth of Guinea grass}

We counted the total number of Guinea grass seedlings weekly and thinned them after three weeks so that only a single seedling remained in each pot. We monitored growth of these seedlings over the course 
of the experiment (14 weeks), after which plants were carefully removed from pots to keep as much of the root intact as possible. We measured the final root length and height at the end of the experiment. We separated the aboveground tissue from roots at the root collar and placed both in a drying oven at $65^{\circ} \mathrm{C}$ for 3-5 days in labeled paper bags. We measured the dry weight of both above- and below-ground tissue.

\section{Germination and growth of native seed bank}

We monitored the total number of native plant seedlings sprouting from the seed bank weekly. At the end of the experiment, we counted the number of native plants present within each pot noting how many were monocots and dicots. We were unable to identify seedlings to species as the plants were juveniles and did not have flowering structures. Therefore, to quantify species richness, we used phenotypic differences

to distinguish morphospecies within each pot (hereafter, referred to as species richness). To measure dry weight of the native community, we placed above- and below-ground tissue in drying ovens at $65^{\circ} \mathrm{C}$ for five days before weighing.

\section{Analyses}

To assess the effect of soil inoculation method and invasion status on Guinea grass growth and germination, we used a mixed effect model to analyze germination, height, root length, and dry biomass. We treated soil inoculation method and invasion status as fixed variables and site as a random variable. We considered Guinea grass germination as the total number of seedlings and did not normalize this number as we used the same mass of seeds $(0.015 \mathrm{~g})$ per pot. We evaluated all data for normality and homogeneity of variance prior to analysis. Germination, height, and biomass data were log-transformed prior to analysis. Three pots had no Guinea grass growth and were removed from analyses.

The effect of soil inoculation method and invasion status on germination and growth of the native plant community was also assessed using mixed-effects models as above. Here we also treated germination as the total number of seedlings that germinated as the amount of bulk soil and inoculum used was the same across all treatments and replicates. As above, all data were assessed to see if they met the assumptions for parametric analysis. Germination and plant abundance were log-transformed prior to analysis, whereas species richness and biomass were transformed using the formula $\log (x+1)$.

To assess effect of autoclaving and invasion on soil characteristics, we assessed for normality and homogeneity of variance. Electrical conductivity, phosphorus, and sulfur were log transformed prior to analysis. Using all data $(n=18)$, we used an analysis of variance (ANOVA) to evaluate the effect of autoclave time. For assessing effect of invasion, we used an ANOVA and included only data from unautoclaved soil ( $\mathrm{n}=6$ samples; 3 from invaded sites and 3 non-invaded sites).

\section{Results}

\section{Effect of soil origin (invaded and non-invaded grasslands)}


Guinea grass height, root length, and biomass were significantly higher when grown in soil from invaded sites versus non-invaded sites (Fig. I; Table II). Overall, germination of Guinea grass did not differ in invaded or non-invaded soil (Table II), but germination within the first week was higher in soil from invaded sites $\left(F_{1,54}=6.86, p=0.0114\right.$; Supplementary Fig. $\left.\mathrm{SI}\right)$. Within the first week, average germination of Guinea grass in invaded soil was $4.1 \pm 4.4$ compared to $1.9 \pm 2.3$ in soil from non-invaded sites.

Table II: Results of ANOVA mixed effect model assessing the effect of soil origin on Guinea grass germination and growth.

\begin{tabular}{|lllllll|}
\hline & \multicolumn{2}{l}{ Invasion status } & Soil treatment & \multicolumn{2}{l|}{ Interaction } \\
\hline & $\mathrm{F}_{1,51}$ & $p$ & $\mathrm{~F}_{1,51}$ & $p$ & $\mathrm{~F}_{1,51}$ & $p$ \\
\hline Seedling germination (total) & 0.71 & n.s. & 7.20 & 0.0098 & 2.44 & n.s. \\
\hline Height $(\mathrm{cm})$ & 38.60 & $<0.0001$ & 0.98 & n.s. & 0.00 & n.s. \\
\hline Root length (cm) & 14.55 & 0.0004 & 0.20 & n.s. & 0.39 & n.s. \\
\hline Biomass $(\mathrm{g})$ & 31.22 & $<0.0001$ & 0.08 & n.s. & 0.03 & n.s. \\
\hline
\end{tabular}

Within the native seed bank, seedling germination, plant abundance, and species richness were significantly higher in soil from non-invaded sites than invaded sites (Fig. II; Table III). Average plant abundance was $54 \pm 21$ in non-invaded soil and $41 \pm 17$ in invaded soil, and average species richness was $8 \pm 2$ species versus $6 \pm 2$, respectively. The native community had higher total biomass (mean $1.3 \mathrm{~g}$ \pm 0.4 ) in soil from invaded sites than non-invaded sites (mean $0.6 \mathrm{~g} \pm 0.3$ ) (Fig. II; Table III).

Table III: Results of ANOVA mixed effect model assessing the effect of soil origin on germination and growth of the native plant community.

\begin{tabular}{|llllllll|}
\hline & \multicolumn{3}{c}{ Invasion } & \multicolumn{3}{c|}{ Soil treatment } & \multicolumn{2}{c|}{ Interaction } \\
\hline & $\mathrm{F}_{1,54}$ & $p$ & $\mathrm{~F}_{1,54}$ & $p$ & $\mathrm{~F}_{1,54}$ & $p$ \\
\hline Seedling germination & 41.89 & $<0.0001$ & 0.03 & n.s. & 2.63 & n.s. \\
\hline Plant abundance & 9.05 & 0.0040 & 5.57 & 0.0219 & 3.09 & n.s. \\
\hline Total biomass (g) & 51.65 & $<0.0001$ & 4.26 & 0.0439 & 0.10 & n.s. \\
\hline Species richness & 4.52 & 0.0382 & 0.02 & n.s. & 0.08 & n.s. \\
\hline
\end{tabular}

\section{Effect of soil inoculation method}

Guinea grass germination, native plant abundance, and total biomass of the native community showed significant differences between the two soil inoculation methods we tested. Soil inoculation method significantly influenced Guinea grass germination with MSS treatments having higher germination (mean 
$21 \pm 15$ ) than ISS treatments (mean $12 \pm 11$ ) (Fig. III; Table II). Within the native plant community, plant abundance and total biomass were higher in ISS treatments (plant abundance: mean $53 \pm 21$; total biomass: mean $1.04 \pm 0.5$ ) than MSS (plant abundance: mean $43 \pm 17$; total biomass $0.85 \pm 0.5$ ) (Fig. II; Table III).

\section{Discussion}

In this study, we assessed PSF processes in South Texas savannahs exploring the effect of Guinea grass invasion on PSF. We found that soil from grasslands already invaded by Guinea grass had a positive effect on growth of Guinea grass with plants growing taller and accumulating more biomass than Guinea grass grown in soil from non-invaded grasslands (Fig. I, Table II). Furthermore, plants germinating from the native seed bank accumulated more biomass when grown in soil from invaded grasslands but had higher species richness and abundance in soil from non-invaded grasslands (Fig. II, Table III). These results indicate the presence of distinct patterns of PSF in invaded and non-invaded grasslands in South Texas with evidence of positive PSF in invaded grasslands and negative PSF in non-invaded, native grasslands. Although we did not condition soil under controlled conditions making it difficult to assign the difference in the direction of PSF to the presence or absence of Guinea grass, the low spatial distance between the invaded and non-invaded grasslands we sampled suggests a reduced role of environmental factors, such as precipitation and temperature, in driving these differences.

Overall, our results were consistent across both methods of soil inoculation, and we found no soil origin X soil inoculation method interaction indicating that there is no method bias. We did find small differences in results between ISS and MSS (Fig. III, Table II and III): Guinea grass germination was higher in MSS treatments than ISS, but native plant abundance and biomass was higher in ISS than MSS. Although we did not assess community composition in this study, differences between the soil inoculation method could be influenced by shifts in the relative abundance of particular community members after pooling inocula or specificity of PSF effects on native versus non-native plant species (Pernilla Brinkman et al. 2010; van de Voorde et al. 2012). It is important to note that these metrics had high levels of variation which could indicate that more replicates are needed to better understand differences in soil inoculation method. Based on these results though, the optimal soil inoculation method is dependent on the main study objective with MSS more appropriate for broad-scale patterns at a regional level and ISS for investigating fine-scale variation at the local level.

The increased growth of Guinea grass and higher biomass of the native community in soil from invaded grasslands could indicate differences in either the microbial community or soil nutrients. A common hypothesis for invasion success is the Enemy Release Hypothesis in which movement of plants to novel environments causes a decrease in negative pressures from pathogen, herbivores, and parasites found in their home range (Keane and Crawley 2002), but focus should also be given to changes in soil nutrient availability. For example, some exotic species in Hawaii release nitrogen from their litter faster than natives increasing soil nitrogen availability for themselves and co-occurring natives (Allison and Vitousek 2004). A meta-analysis of effect of invasive plants on soil communities and nutrient cycling indicated 
that invasive plants support decomposers and rhizosphere mutualists (Zhang et al. 2019). When we assessed differences in soil characteristics though, we found no significant difference, although many soil nutrients were higher in invaded soil than in non-invaded soil (Supplementary fig. SII). Alternatively, invasion of non-native plants may cause cascading effects on conspecific native species through allelopathy as examples of the Novel Weapons Hypothesis (Callaway and Ridenour 2004). Allelopathic effects have been found to decrease with increasing phylogenetic distance (Zhang et al. 2021), so species of monocot should be more negatively impacted than dicots in invaded grasslands When we assessed differences in the effect of PSF on monocots and dicots, monocot species richness and plant abundance were higher in soil from non-invaded sites than invaded sites, whereas dicots showed no difference (Supplementary fig. SIII). Although overall PSF in soil from invaded grasslands was positive, these results seem to indicate that Guinea grass has a stronger negative effect on monocot species that are more closely related to Guinea grass phylogenetically. These results raise questions that we could test in the future, such as whether negative feedback is driving species coexistence in non-invaded communities and whether guinea grass invasion is causing the switch to an overall positive feedback mechanism while simultaneously suppressing other monocot species. In future work, we aim to parse out the effect of Guinea grass invasion on soil nutrients, allelopathy, and soil microbial communities in order to better understand how Guinea grass impacts PSF processes.

In conclusion, we found evidence for strong differences in PSF as a function of invasion with negative PSF in non-invaded, native grasslands and positive PSF in grasslands invaded by Guinea grass. These results were robust to soil inoculation method indicating that either method of inoculation would be adequate in this system. Our results represent the first time PSF processes have been studied in South Texas savannahs and show how Guinea grass, an emerging invasive within the southern United States, influences these processes.

\section{Declarations}

\section{Acknowledgements}

L. Miksch for assistance with the experiment and commons on the manuscript; A. Leo and A. Rhodes for comments on manuscript. The Lee and Ramona Bass Foundation for funding and access to study areas.

Funding Funding for this project was provided by the Lee and Ramona Bass foundation.

Competing interests The authors declare no competing financial interests.

Code availability

In order to support open science and data reproducibility, all data and scripts used for analyses are available in the eabowman/Bowmanetal-STexasGuineaGrass-PlantSoilFeedback repository on GitHub, [Zenodo permanent link].

\section{References}


Allison SD, Vitousek PM (2004) Rapid nutrient cycling in leaf litter from invasive plants in Hawai'i. Oecologia 141:612-619. https://doi.org/10.1007/s00442-004-1679-z

Ammondt SA, Litton CM (2012) Competition between Native Hawaiian Plants and the Invasive Grass Megathyrsus maximus: Implications of Functional Diversity for Ecological Restoration. Restor Ecol 20:638-646. https://doi.org/10.1111/j.1526-100X.2011.00806.x

Ammondt SA, Litton CM, Ellsworth LM, Leary JK (2013) Restoration of native plant communities in a Hawaiian dry lowland ecosystem dominated by the invasive grass Megathyrsus maximus. Appl Veg Sci 16:29-39. https://doi.org/10.1111/j.1654-109X.2012.01208.x

Assessment ME (2005) Ecosystems and human well-being: Synthesis. Washington, D.C.

Batten KM, Scow KM, Davies KF, Harrison SP (2006) Two invasive plants alter soil microbial community composition in serpentine grasslands. Biol Invasions 8:217-230. https://doi.org/10.1007/s10530-0043856-8

Belnap J, Phillips SL, Sherrod SK, Moldenke A (2005) Soil biota can change after exotic plant invasion: Does this affect ecosystem processes? Ecology 86:3007-3017. https://doi.org/10.1890/05-0333

Bever JD (1994) Feedback between plants and their soil communities in an old field community. Ecology 75:1965-1977. https://doi.org/10.2307/1941601

CABI (2021) Megathyrsus maximus (Guinea grass). https://www.cabi.org/isc/datasheet/38666

Cahill JF, Cale JA, Karst J, et al (2017) No silver bullet: Different soil handling techniques are useful for different research questions, exhibit differential type I and II error rates, and are sensitive to sampling intensity. New Phytol 216:11-14. https://doi.org/10.1111/nph.14141

Callaway RM, Ridenour WM (2004) Novel weapons: Invasive success and the evolution of increased competitive ability. Front Ecol Environ 2:436-443. https://doi.org/10.1890/15409295(2004)002[0436:NWISAT]2.0.C0;2

Chou CH, Young CC (1975) Phytotoxic substances in twelve subtropical grasses. J Chem Ecol 1:183193. https://doi.org/10.1007/BF00987867

D'Antonio C, Flory SL (2017) Long-term dynamics and impacts of plant invasions. J Ecol 105:14591461. https://doi.org/10.1111/1365-2745.12879

Dogra KS, Sood SK, Dobhal PK, Sharma S (2010) Alien plant invasion and their impact on indigenous species diversity at global scale: A review. J Ecol Nat Environ 2:175-186.

Ellsworth LM, Litton CM, Leary JJK (2015) Restoration impacts on fuels and fire potential in a dryland tropical ecosystem dominated by the invasive grass Megathyrsus maximus. Restor Ecol 23:955-963. 
Gundale MJ, Wardle DA, Kardol P, Nilsson MC (2019) Comparison of plant-soil feedback experimental approaches for testing soil biotic interactions among ecosystems. New Phytol 221:577-587. https://doi.org/10.1111/nph.15367

Hawkes C V., Kivlin SN, Du J, Eviner VT (2013) The temporal development and additivity of plant-soil feedback in perennial grasses. Plant Soil 369:141-150. https://doi.org/10.1007/s11104-012-1557-0

Hawkes C V., Wren IF, Herman DJ, Firestone MK (2005) Plant invasion alters nitrogen cycling by modifying the soil nitrifying community. Ecol Lett 8:976-985. https://doi.org/10.1111/j.14610248.2005.00802.x

Keane RM, Crawley MJ (2002) Exotic plant invasions and the enemy release hypothesis. Trends Ecol Evol 17:164-170. https://doi.org/10.1016/S0169-5347(02)02499-0

Kulmatiski A, Beard KH, Stevens JR, Cobbold SM (2008) Plant-soil feedbacks: A meta-analytical review. Ecol Lett 11:980-992. https://doi.org/10.1111/j.1461-0248.2008.01209.x

Lekberg Y, Bever JD, Bunn RA, et al (2018) Relative importance of competition and plant-soil feedback, their synergy, context dependency and implications for coexistence. Ecol Lett 21:1268-1281. https://doi.org/10.1111/ele.13093

Levine JM, Pachepsky E, Kendall BE, et al (2006) Plant-soil feedbacks and invasive spread. Ecol Lett 9:1005-1014. https://doi.org/10.1111/j.1461-0248.2006.00949.x

Pernilla Brinkman E, Van der Putten WH, Bakker EJ, Verhoeven KJF (2010) Plant-soil feedback: Experimental approaches, statistical analyses and ecological interpretations. J Ecol 98:1063-1073. https://doi.org/10.1111/j.1365-2745.2010.01695.x

Pyšek P, Richardson DM (2010) Invasive species, environmental change and management, and health. Annu Rev Environ Resour 35:25-55. https://doi.org/10.1146/annurev-environ-033009-095548

Ramirez-Yanez LE, Ortega-S JA, Brennan LA, Rasmussen GA (2007) Use of Prescribed Fire and Cattle Grazing To Control Guineagrass. 23Rd Tall Timbers Fire Ecol Conf Fire Grassl Shrubl Ecosyst 240-245

Reinhart KO, Callaway RM (2006) Soil biota and invasive plants. New Phytol 170:445-457. https://doi.org/10.1111/j.1469-8137.2006.01715.x

Reinhart KO, Rinella MJ (2016) A common soil handling technique can generate incorrect estimates of soil biota effects on plants. New Phytol 210:786-789. https://doi.org/10.1111/nph.13822

Rhodes AC, Plowes RM, Goolsby JA, et al The dilemma of Guinea grass (Megathyrsus maximus): a valued pasture grass and an emergent invasive species 
Sands D, Goolsby JA (2011) The Case for Biological Control of Exotic African Grasses in Australia and USA Using Introduced Detritivores. 103-111

Sarmiento C, Zalamea P-C, Dalling JW, et al (2017) Soilborne fungi have host affinity and host-specific effects on seed germination and survival in a lowland tropical forest. Proc Natl Acad Sci 114:1145811463. https://doi.org/10.1073/pnas.1706324114

van de Voorde TFJ, van der Putten WH, Bezemer TM (2012) Soil inoculation method determines the strength of plant-soil interactions. Soil Biol Biochem 55:1-6.

https://doi.org/10.1016/j.soilbio.2012.05.020

Van der Putten WH, Bardgett RD, Bever JD, et al (2013) Plant-soil feedbacks: The past, the present and future challenges. J Ecol 101:265-276. https://doi.org/10.1111/1365-2745.12054

van der Putten WH, Bradford MA, Pernilla Brinkman E, et al (2016) Where, when and how plant-soil feedback matters in a changing world. Funct Ecol 30:1109-1121. https://doi.org/10.1111/13652435.12657

Van Der Putten WH, Kowalchuk GA, Brinkman EP, et al (2007) Soil feedback of exotic savanna grass relates to pathogen absence and mycorrhizal selectivity. Ecology 88:978-988.

https://doi.org/10.1890/06-1051

Wied JP, Perotto-Baldivieso HL, Conkey AAT, et al (2020) Invasive grasses in South Texas rangelands: historical perspectives and future directions. Invasive Plant Sci Manag 13:41-58. https://doi.org/10.1017/inp.2020.11

Wolfe BE, Klironomos JN (2005) Breaking New Ground: Soil Communities and Exotic Plant Invasion. Bioscience 55:477. https://doi.org/10.1641/0006-3568(2005)055[0477:bngsca]2.0.co;2

Zalamea PC, Sarmiento C, Elizabeth Arnold A, et al (2015) Do soil microbes and abrasion by soil particles influence persistence and loss of physical dormancy in seeds of tropical Pioneers? Front Plant Sci 5:799. https://doi.org/10.3389/fpls.2014.00799

Zhang P, Li B, Wu J, Hu S (2019) Invasive plants differentially affect soil biota through litter and rhizosphere pathways: a meta-analysis. Ecol. Lett. 22:200-210

Zhang Z, Liu Y, Yuan L, et al (2021) Effect of allelopathy on plant performance: a meta-analysis. Ecol Lett 24:348-362. https://doi.org/10.1111/ele.13627

(2021) U.S. Climate Data

\section{Figures}



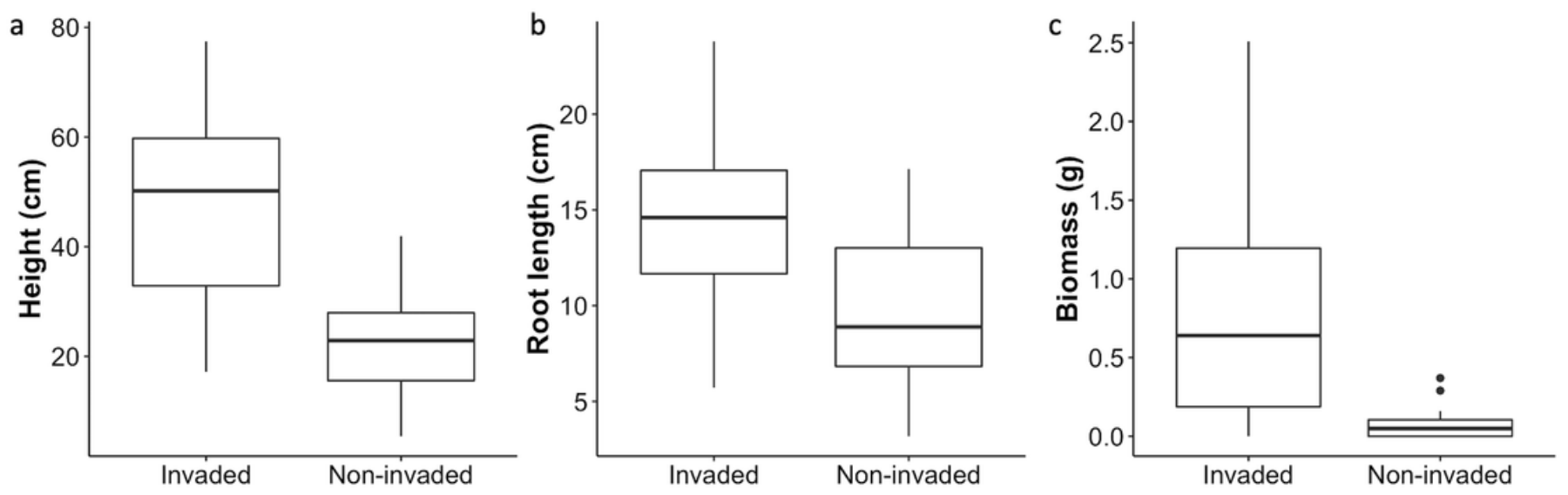

\section{Figure 1}

Guinea grass height (a), root length (b), and biomass (c) when grown in soil collected from grassland invaded by conspecifics and non-invaded grasslands dominated by native species. All data shown are non-transformed. 

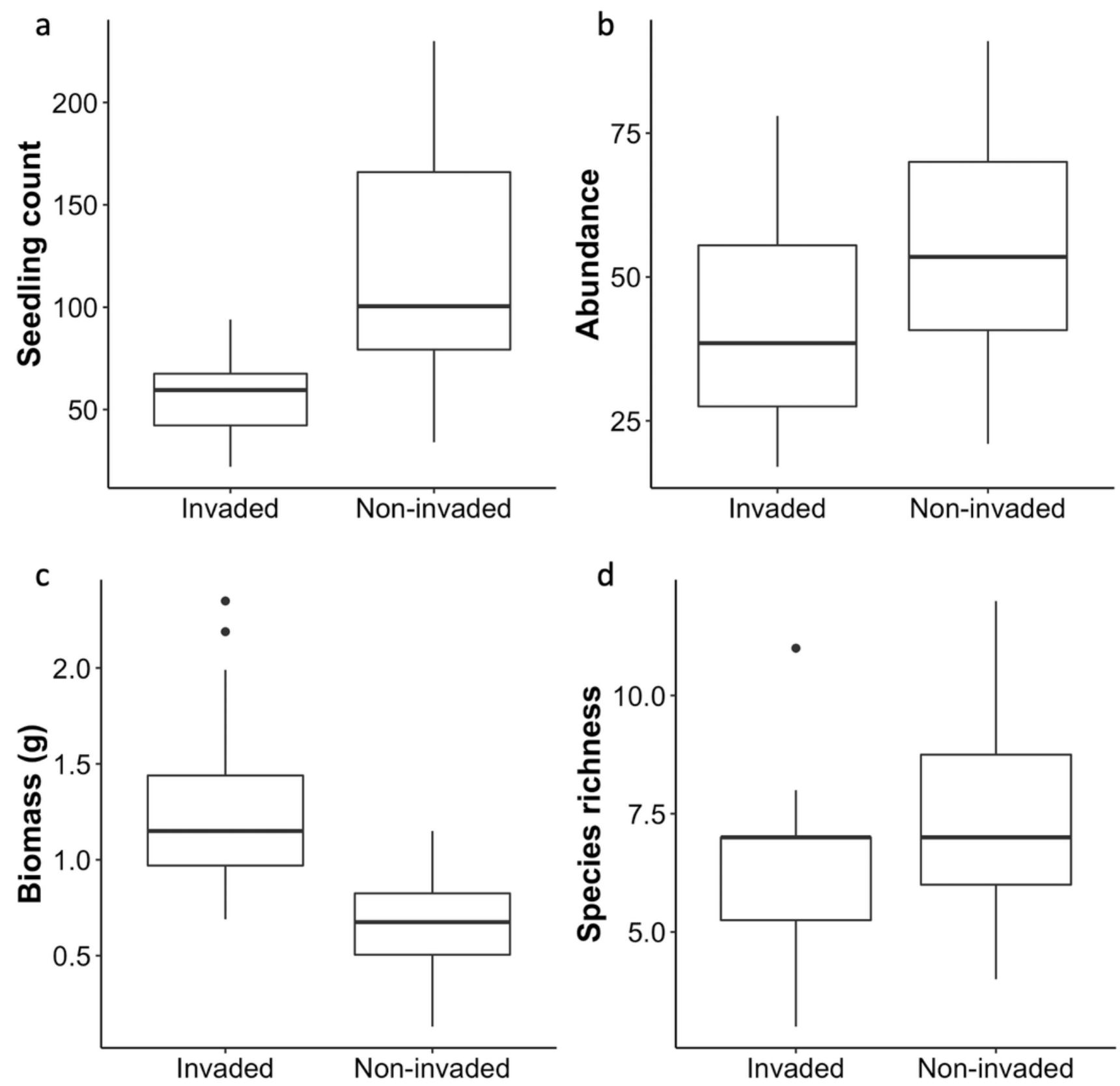

Figure 2

Seedling count (a), abundance (b), biomass (c), and species richness (d) of native plant community when grown in soil from Guinea grass invaded and non-invaded grasslands. All data shown are nontransformed. 

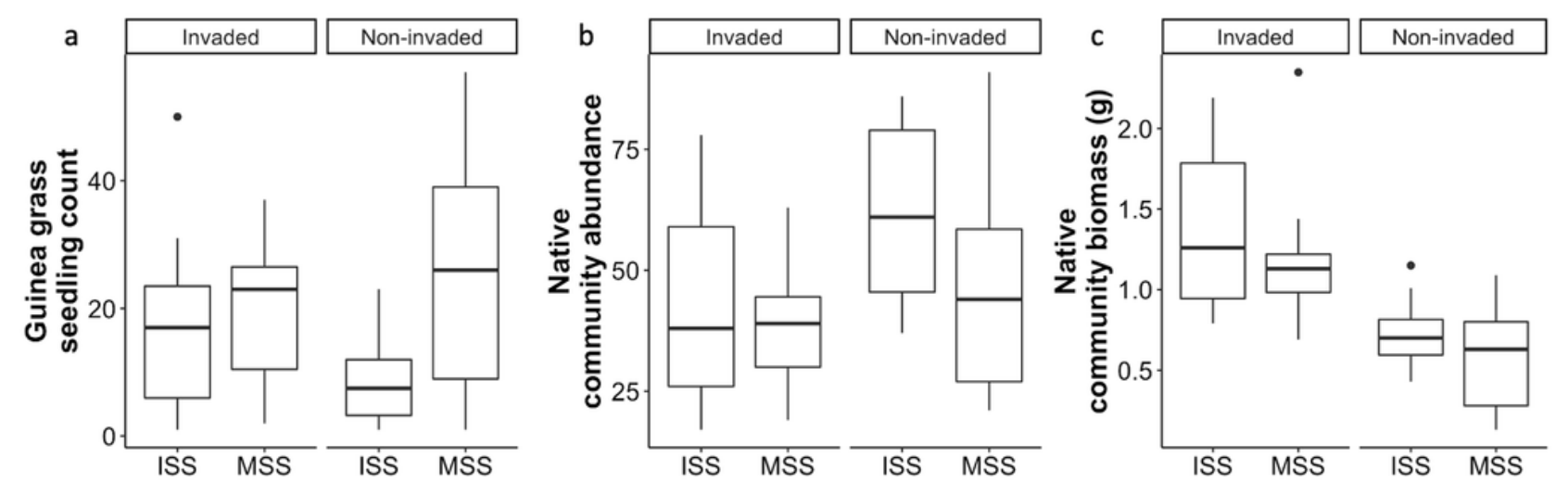

\section{Figure 3}

Effect of soil treatment on Guinea grass seedling count (a), native community plant abundance (b), and native community biomass (c). MSS: mixed soil sampling; ISS: individual soil sampling. All data shown are non-transformed.

\section{Supplementary Files}

This is a list of supplementary files associated with this preprint. Click to download.

- SupplementaryFigSI.tiff

- SupplementaryFigSII.tiff

- SupplementaryFigSIII.tiff

- SupplementaryTable.docx 